\title{
Síntese de Biodiesel pela Reação de Transesterificação Básica com Óleo de Soja
}

\author{
Hosana M. L. de Almeida, Ellen S. A. Duarte \& José G. V. Neto
}

O biodiesel é um combustível adquirido de fontes renováveis, que diminui o lançamento de gases poluentes para o meio ambiente, gases de efeito estufa, e sulfetos tóxicos, podendo ser conveniente o reaproveitamento de biomassas antes inutilizáveis. A síntese de biodiesel de óleo de soja se mostra como uma alternativa aos combustíveis de origem fóssil, não poluidora ao meio ambiente, geradora de proventos para populações desprovidas de renda. Foram sintetizadas 65 amostras de biodiesel por rota etílica em meio básico e analisados suas características físico-químicas de acordo com a Agência Nacional do Petróleo, Gás Natural e Biocombustível (ANP), considerando-se os parâmetros índice de acidez, índice de saponificação, densidade e viscosidade com a finalidade de verificação da qualidade das mesmas.

\section{Palavras-chave: Biodiesel; Óleo de Soja; Análise Físico-Química.}

Biodiesel is a package purchased from renewable sources, which reduce the emission of greenhouse gases, greenhouse gases, and toxic sulfides, which may be convenient or reuse of previously unusable biomass. A synthesis of biodiesel from soybean oil shows itself as an alternative to fossil fuels, it is not a solution for the environment, which generates income for populations without income. Sixty-five biodiesel samples were synthesized per ethylic route in basic medium and analyzed their physico-chemical characteristics according to the National Agency of Petroleum, Natural Gas and Biofuel (ANP), considering the index index index, saponification index, density and viscosity in order to.

Keywords: Biodiesel; Soybean Oil; Physicochemical Analysis. 


\section{Introdução}

O biodiesel é um combustível derivado de fontes de biomassa que podem ser obtidos a partir de óleos vegetais provenientes de atividade agroindustriais (COSTA et al, 2015). Por causa da escassez de extração de petróleo em reservas mundiais o biodiesel vem sendo amplamente estudado como forma de aditivo em motores ou até mesmo a sua substituição, uma vez que este não emite moléculas poluentes para o meio ambiente como sulfetos tóxicos, também auxiliando a renda de populações que vivem na agricultura familiar podendo ser obtido através de culturas regionais como pinhão manso, semente de girassol, buriti, dendê. Podendo ser obtido através da reação de transesterificação com um catalizador ácido ou básico na presença de álcool formando uma mistura de alquil-ésteres.

Tendo em vista as oportunidades, o governo brasileiro vem ampliando os investimentos de matéria prima para que essa fonte renovável de energia possa garantir emprego e renda para as populações diminuindo os impactos ambientais.

Dentre as muitas fontes de biomassa já disponíveis, óleos vegetais dominam a produção de biodiesel (mais de $80 \%$ ) e têm sido amplamente utilizados em programas de energia renovável devido suas inúmeras vantagens intrínsecas. Países como Brasil, Argentina, Reino Unido e Japão, além de diversos membros da União Europeia, têm investido significativamente na produção e disponibilidade comercial de biodiesel obtido a partir de óleos vegetais (OECD/FAO, 2014).

Tendo em vista a importância do biocombustível a partir de fontes renováveis, como forma de redução de matérias primas obtida de fontes de petróleo, reduzindo os impactos ambientais gerados por motores a combustão, o presente projeto tem como objetivos a produção de biocombustíveis a partir de óleo de soja e sua caracterização física (densidade, refração e viscosidade) e química (índice de acidez e índice de saponificação) em amostras de biodiesel de soja de acordo com a legislação vigente.

\section{Metodologia}

\section{SÍNTESE DAS AMOSTRAS DE BIODIESEL}

As amostras de biodiesel foram sintetizadas utilizandose $0,75 \% \mathrm{~m} / \mathrm{m}$ de hidróxido de potássio $(\mathrm{KOH})$ como catalisador, razão molar de 6:1 metanol/óleo, temperatura reacional de $55{ }^{\circ} \mathrm{C}$ e $50 \mathrm{~g}$ do óleo de soja. O óleo foi adicionado a um balão de duas vias acoplado a um sistema de refluxo com agitação e aquecimento constantes. A mistura do catalisador com o álcool foi adicionada ao sistema e mantida sob agitação e aquecimento durante 1 hora. Posteriormente, o biodiesel foi colocado em um funil de decantação e, decorridos 15 minutos, retirou-se a glicerina. O biodiesel obtido foi então lavado com água destilada à temperatura ambiente até que o mesmo atingisse $\mathrm{pH}$ neutro. Adicionou-se sulfato de sódio anidro e filtrou-se a mistura com papel de filtro qualitativo (80g Unifil,com diâmetro $12,5 \mathrm{~cm}$ ) no sistema de filtração a vácuo para remover resíduos da água de lavagem.

\section{CARACTERIZAÇÃO FÍSICO-QUÍMICA}

Adquiriram-se onze lotes de óleo de soja de diferentes marcas para a síntese do biodiesel. Foram sintetizadas 11 amostras de biodiesel com o óleo de soja puro e 54 amostras a partir da mistura 1:1 dos lotes adquiridos, sujeitas a caracterizações realizadas através das resoluções número 07/2008 e 14/2012 da Agência Nacional do Petróleo, Gás Natural e Biocombustível (ANP). Considerando-se os parâmetros físico-químicos, índice de acidez, índice de saponificação, densidade e viscosidade com a finalidade de verificação da qualidade das mesmas. Todo o procedimento de caracterização físico-química foi realizado em triplicata e de forma completamente aleatória.

Para a determinação do índice de acidez, primeiramente pesou-se $1 \mathrm{~g}$ da amostra de biodiesel em um erlenmeyer e adicionou-se $12,5 \mathrm{~mL}$ de álcool etílico. Em seguida, foi adicionada uma gota de fenolftaleína $1 \% \mathrm{~m} / \mathrm{v}$, titulando-se com $\mathrm{NaOH} 0,1 \mathrm{~mol} / \mathrm{L}$ até adquirir a coloração rósea (BRASIL - ANP, 2012). 
Na determinação do índice de saponificação, pesouse $1 \mathrm{~g}$ da amostra de biodiesel em um erlenmeyer e, em seguida, adicionou-se $12,5 \mathrm{~mL}$ da solução alcoólica de hidróxido de potássio $4 \% \mathrm{~m} / \mathrm{v}$. Realizado o procedimento, foi utilizado em sistema de refluxo, com aquecimento adaptando-se o erlenmeyer, durante 30 minutos de aquecimento a $60^{\circ} \mathrm{C}$. Logo após foi adicionada uma gota de fenolftaleína $1 \% \mathrm{~m} / \mathrm{v}$ e titulou-se a quente com ácido clorídrico a $0,5 \mathrm{~mol} / \mathrm{L}$ até o ponto de equivalência (desaparecimento da cor rosa).

A densidade foi determinada utilizando-se um densímetro digital Mettler Toledo, Densito 30PX a 25 ${ }^{\circ} \mathrm{C}$, segundo metodologia recomendada pela Agência Nacional do Petróleo, Gás Natural e Biocombustível (BRASIL - ANP, 2008).

A viscosidade foi determinada com o uso do viscosímetro de Ostwald com capilar de 200. Colocou-se o biodiesel em um banho térmico a $40^{\circ} \mathrm{C}$, e verificou-se o tempo de escoamento do fluido. $\mathrm{O}$ mesmo procedimento foi realizado pela a água utilizada como fluido padrão.

A refração foi determinada com o refratômetro de Abbe, onde foi colocadas gotas do biodiesel sobre a superfície do equipamento, em um ambiente com luminosidade, foi possível identificar a faixa colorida observada pelo ocular direito do refratômetro. Leu-se o índice de refração diretamente na escala.

\section{Resultados e Discussão}

Durante o processo de transesterificação dos óleos, problemas relacionados à baixa taxa de conversão dos óleos a biodiesel ocorreram, além dos produtos de reação (biodiesel e glicerol) formar uma única fase, o que dificultou a separação destes coprodutos e requereu um gasto excessivo de água para lavagem do biodiesel produzido. Adicionalmente, o biodiesel obtido degradava-se rapidamente e alguns de seus parâmetros físico-químicos, tais como: índice de acidez e viscosidade, encontrava-se completamente fora dos limites estabelecidos pela Agência Nacional de Petróleo, Gás Natural e Biodiesel (ANP).
Para superar estes inconvenientes, diversas metodologias de síntese (como catálise ácida usando ácido sulfúrico e catálise básica usando hidróxido de sódio ou hidróxido de potássio) foram testadas. A utilização de metanol e etanol também foi avaliada, mas todas sem o devido sucesso. A partir daí, passouse a investigar quais os possíveis fatores que poderiam interferir o meio reacional. Observando-se a composição química informada em seus respectivos rótulos, verificou-se que os óleos de soja continham ácido cítrico e/ou terc-butil-hidroquinona (TBHQ). O ácido cítrico é usado como agente quelante/sequestrante que complexa íons metálicos, principalmente cobre e ferro, que catalisam a oxidação lipídica. Neste caso, um par de elétrons não compartilhado na sua estrutura molecular promove a ação de complexação.

Já o TBHQ é um pó cristalino branco e brilhoso, moderadamente solúvel em óleos e gorduras e não se complexa com íons de cobre e ferro, além de ser considerado o melhor antioxidante para óleos de fritura, pois resiste ao calor e proporciona uma excelente estabilidade para os produtos acabados. Ácido cítrico e TBHQ apresentam excelente sinergia em óleos vegetais. No Brasil, o teor de TBHQ em óleos vegetais pode chegar até 200 ppm, segundo limita o Ministério da Saúde.

Estes compostos podem, portanto, ter afetado significativamente as condições reacionais testadas, uma vez que eles aumentam a estabilidade química e térmica dos ácidos graxos presentes, dificultando o processo de transesterificação. Após esta constatação, buscou-se na literatura outra rota para síntese dos biodieseis, optandose pela metodologia descrita por Costa e colaboradores (2015) com adaptações. Assim, para síntese dos biodieseis por rota etílica catalisada por hidróxido de sódio, foram então utilizadas $50 \mathrm{~g}$ de óleo de soja, $22 \mathrm{ml}$ de etanol e $1 \mathrm{~g}$ de hidróxido de sódio.

Foram, então, sintetizadas 65 amostras de biodiesel utilizando 11 amostras de óleo de soja e 54 misturas binárias delas.

Os parâmetros físico-químicos dos biodieseis sintetizados são apresentados na Tabela 1 . 
Tabela 1. Parâmetros físico-químicos da análise de biodiesel com óleo de soja.

\begin{tabular}{|c|c|c|c|c|c|}
\hline & $\begin{array}{c}\text { Viscosidade } \\
\text { cinemática (mm2/s) }\end{array}$ & Refração & Densidade (g/cm3) & $\begin{array}{c}\text { Índice de acidez (mg } \\
\mathrm{KOH} / \mathrm{g})\end{array}$ \\
\hline Média & 2,99 & 1,53 & 0,87 & 0,36 & 0,19 \\
\hline Mínimo & 2,67 & 1,51 & 0,73 & 0,51 & 159,62 \\
\hline Máximo & 3,26 & 1,54 & 0,88 & 0,10 & 132,84 \\
\hline Desvio-padrão & 0,13 & 0,01 & 0,02 & 26,82 & 15,90 \\
\hline Coef. de variação (\%) & 4,28 & 0,51 & 2,58 & 26,54 & 9,96 \\
\hline
\end{tabular}

Os valores obtidos para o índice de acidez apresentaramse dentro do recomendado pela ANP (2014), que estabelece o limite de $0,5 \mathrm{mg} \mathrm{KOH} / \mathrm{g}$ de biodiesel. Já para o índice de saponificação, a ANP recomenda apenas a anotação do valor, não estabelecendo limites. A maioria dos biodieseis apresentaram valores de densidade dentro da faixa recomendada, que é de 0,805 a $0,9 \mathrm{~g} / \mathrm{cm} 3$. Assim como os valores de viscosidade estiveram dentro dos valores recomendados, que é de 3,0-6,0 mm2/s1. O índice de refração não é estabelecido limites de acordo com a normativa. Como pode ser observado, o coeficiente de variação dos dados é muito baixo (abaixo de $10 \%$ ) para todos os parâmetros medidos, exceto para o índice de acidez que é superior a $26 \%$.

\section{Conclusões}

A obtenção do biodiesel com óleo de soja comercial obteve resultados satisfatórios apesar da presença de ácido cítrico e/ou terc-butil-hidroquinona (TBHQ), percebeu-se um menor consumo de água de lavagem quando comparado às primeiras metodologias usadas, para produção de biodiesel. Neste caso, sendo capaz de atingir as expectativas dos parâmetros físico-químicos de acordo com a norma estabelecida.

\section{Agradecimentos}

Agradecemos aos técnicos da Universidade Estadual da Paraíba e ao CNPQ pelo consentimento da pesquisa.

\section{Referências Bibliográficas}

1. Costa, G.B.; Fernandes, D.D.S.; Almeida, V.E.; Araújo, T.S.P.; Melo, J.P.; Diniz, P.H.G.D.; Véras, G. Digital image-based classification of biodiesel. Talanta, 139 (2015) 50-55.

2. OECD/FAO (2014), "Biofuels", em: OECD/FAO Agricultural Outlook 2014, OECD Publishing.

3. Brasil. Agência nacional de petróleo, gás natural e biocombustíveis (ANP). Resolução No 03, 13/08/2014. Especificação do Biodiesel. Diário Oficial da União, 26/08/2014.

4. Brasil. Agência nacional de petróleo, gás natural e biocombustíveis (ANP). Resolução No 14, 11/05/2012. Especificação do Biodiesel. Diário Oficial da União, 18/05/2012.

\section{Hosana M. L. de Almeida, Ellen S. A. Duarte \& José G. V. Neto}

Universidade Estadual da Paraíba, UEPB, Brasil.

*E-mail: hosana.limaalmeida@gmail.com 